\title{
An exercise to teach bioscience students about plagiarism
}

Chris J.R. Willmott* and Tim M. Harrison

Department of Biochemistry, University of Leicester, Leicester, LE1 7RH, UK

Tel: +44 (0) 1162522094

E-mail address: cjrw2@le.ac.uk

* Author for correspondence

Running title: bioscience plagiarism exercise

Key word: plagiarism

Brief description: An exercise to help bioscience students distinguish between appropriate and inappropriate use of source materials. 
An exercise to teach bioscience students about plagiarism

Brief description: An exercise to help bioscience students distinguish between appropriate and inappropriate use of source materials. 


\begin{abstract}
Plagiarism is an issue of increasing concern to educators, yet students are not always clear about the boundaries between acceptable and unacceptable practice. An exercise to help bioscience students make this important distinction is described.
\end{abstract}

Introduction: There is an old joke to the effect that quoting from one source is copying, from two sources is plagiarism and from three or more is research. The deliberate or accidental re-presentation of somebody else's work as your own is certainly not a new phenomenon, but it has become a matter of pressing relevance in current education. One reason for the renewed interest in plagiarism has clearly been the rise of the internet as a source of material, and a range of software packages have become available for tracking down examples of plagiarism after they have been perpetrated. Believing, however, that prevention is better than cure (and certainly better than mere confirmation of guilt) we have introduced teaching about plagiarism into our first year undergraduate programmes. This includes the exercise described here to illustrate the difference between appropriate and inappropriate use of source materials. It has initially been used as part of our Key Skills programme for Medical Biochemistry and Medical Genetics students, but has also be used in introductory tutorials with first year undergraduates on a wider range of bioscience courses. It could be used equally well with A level biologists and could easily be adapted for an alternative audience.

Description of the exercise: After a brief introduction students are given the worksheet (Figure 1) and asked to decide which of the versions of the original are 
guilty of plagiarism and which are not. They are then given about ten minutes to work through the sheet individually before feedback and discussion.

During the discussion, the following points are drawn out about the different versions of the essay on the worksheet:

1. The first version listed is an 'ice-breaker'. It is clearly a verbatim account and is thus seriously guilty of plagiarism.

2. The second version is marginally better, but is still not acceptable. The original work has been acknowledged as a source of ideas and information, but no indication has been made that the text itself has actually been used.

3. In this case the addition of quote-marks makes an important distinction form the previous versions. The author is clearly acknowledging that both the ideas and the word order have come from the textbook. It is not therefore guilty of plagiarism. We include this version to highlight a different weakness, namely that stringing together a series of quoted chucks of text is a poor way to construct an essay and work written in this way is therefore likely to score low marks.

4. This version of the essay is fine. The quotation is indicated and is used in an appropriate way; it is being critiqued by the author and contrasted with a view supported by a second reference. Not plagiarised.

5. Here we get to the crux of the matter. The fifth and sixth versions of the essay are illustrations of practice that undergraduate students early in their studies consider acceptable but we do not. They are derivatives of the original work with only cosmetic alterations. The wording and sentence 
construction of version 5 bears a very close relationship with the source and is guilty of plagiarism.

6. Similarly, this is a 'thesaurused' or word-swapping version of the same text. A few words have been replaced with synonyms but this is not sufficient to be considered new work.

7. The author of the final essay has made a serious attempt to produce a novel account of the subject. It is still not perfect - lined up as it is here with one original source document there are still echoes of the thought processes within the work and we would ideally want the student to draw on a number of sources in order that the essay has genuine originality. Nevertheless, significant effort has gone into bringing freshness to the text and we would consider that this is not guilty of plagiarism.

This exercise is delivered as part of a session on locating, using and citing suitable reference materials. We also give practical advice on strategies to avoid accidental plagiarism. These include care at the note-taking stage to identify direct quotes (e.g. by use of a highlighter pen or a box around the text) to avoid returning later to the notes and inadvertently remembering them as being further from the original than in fact they are. We encourage the students to take a short break between reading their textbook and submitting anything to paper, so that they are less likely to reproduce word for word the original material.

Over the last three years, this session has been warmly received by our students. In feedback questionnaires from a recent cohort over $50 \%$ of respondents identified the tutorial on plagiarism and referencing as the one in the module from which 
they had learnt the most. "Before this session I had no idea about the rules on plagiarism" wrote one. "The problem of plagiarism was made clear and we were taught how to avoid its use" (sic) added a second. Given that the occurrence of plagiarism in a first year course essay was the original impetus for the introduction of this exercise, it is gratifying that we have detected no similar problems in essays written since the tutorial was introduced.

\section{References}

Rang H.P., Dale M. and Ritter J.M. (1999) Pharmacology, $4^{\text {th }}$ edition. p.657

Edinburgh: Churchill Livingstone

WHO (2000) Global Tuberculosis Control World Health Organisation report 2000

Geneva Switzerland (available online at

http://www.who.int/gtb/publications/globrep00/PDF/GTBR2000full.pdf , accessed April 15 th 2002) 